\title{
Prevalence Of Depression And Associated Factors Among Patients Attending Orthopeadic Outpatient Clinics At Hospitals Of Wolaita, Southern Ethiopia.
}

Adanech Minda

Wolaita Sodo University

Shimelash Bitew Workie ( $\nabla$ sbitew0@gmail.com )

Wolaita Sodo University

Cherinet Leka

Wolaita Sodo University

Dawit Worku

Wolaita Sodo University

\section{Research Article}

Keywords: depression, prevalence, orthopedic trauma, Ethiopia.

Posted Date: February 28th, 2022

DOI: https://doi.org/10.21203/rs.3.rs-1380510/v1

License: (c) (i) This work is licensed under a Creative Commons Attribution 4.0 International License.

Read Full License 


\section{Abstract}

Background: Psychiatric disorders and behavioral disturbances are reported to be three to five times more common among people with injuries. Depressive disorders are the common reported psychiatric problem among trauma survivors. The aim was to assess the magnitude of depression and associated factors among orthopedic trauma patients attending Wolaita Sodo town hospitals.

Methods: A facility-based cross-sectional study was conducted with 359 systematic randomly sampled orthopedic patients. A structured questionnaire was used for data collection. The data were analyzed using SPSS version 20 . The bivariate analysis was done and all explanatory variables which have an association with the outcome variable at $p$-value $<0.25$ were selected for multivariable analysis. Variables that were statistically significant at P-value $<0.05$ were declared using an adjusted odds ratio with a $95 \%$ confidence interval.

Result: A total of 352 orthopedic patients were responded which makes a $98 \%$ response rate. More than half, $193(54.8 \%)$ of respondents were male. Overall depression among respondents was $36.4 \%$ with $95 \%$ Cl [31.4, 41.4]. Pain (AOR 4.42; 95\% Cl [1.49, 13.1]), complication (AOR $5.6[95 \% \mathrm{Cl} 3.02,10.38]$ ), amputation (AOR $3.2(95 \% \mathrm{Cl}[1.64,6.1])$ and multiple site injury (AOR $2.6[95 \% \mathrm{Cl} 1.005,6.64])$ had statistically significant association with depression.

Conclusion and Recommendation: - Depressive disorders are a common phenomenon among orthopedic patients. Having pain, having complications, being amputated, and having multiple site injuries were predictors of depression. Clinicians working at orthopedic clinics emphasize patients' psychological state during the evaluation, especially for amputated patients, and those having multiple site injuries, develop a complication, patients who undergo amputation, and those patients with severe pain.

\section{Introduction}

Mental illness is a global issue according to the World Health Organization (WHO) report more than 450 million people are affected by mental illness(1). Globally, depression is one of the three leading causes of disease and it will be the second leading cause of world disability by 2030. Depression is a disease of the global burden affecting 350 million people worldwide (2). It is estimated that $4.4 \%$ of the global population suffers from a depressive disorder. The prevalence of depression differs from place to place in the world; in which $3.6 \%$ in the western pacific regions to $5.4 \%$ in the African region respectively(1). The prevalence of depression in Sub-Saharan Africa ranges from 15 to $30 \%$ (2). Estimated number of people living with depression increased by $18.4 \%$ between 2005 and 2015 globally (3). According to mental health survey, the prevalence of depression in high income countries is $15 \%$, (4) in low and middle-income countries (LMIC) ranged from $11.1 \%$ to $53 \%$ (2). In Ethiopia, depression was found to be the seventh leading cause of disease burden(5). According to the National Health Survey, conducted in Ethiopia, the prevalence of depression in the general population was $9.1 \%(6)$. 
The lifetime risk of suicide in patients with untreated major depressive disorder is nearly $20 \%$; with appropriate treatment, $70-80 \%$ of patients with major depressive disorder(MDD) achieve significant reductions in symptoms(7). Depression has many causes and risk factors, including mood disturbance, genetic vulnerability, chronic stressful life, use of psychoactive substances, unemployment, life events such as the death of a loved one, physical illness, and medical problems.(1) Evidence shows that several of these forces interact to bring depression. Depressive disorders can be categorized as mild, moderate, and sever(8).

Orthopedic trauma is defined as a severe injury to part of the musculoskeletal system, such as bones, joints, and ligaments. In Ethiopia most of the musculoskeletal injuries result from road traffic accidents, other causes of trauma includes gunshot, slips, a tree falls, and attack by animals, fighting injuries, and industrial accidents. From world-wide reports every day, 16000 people die from injury, and orthopedic traumatic injury accounts for $16 \%$ of the total burden of disease, this makes it the leading cause of mortality(9). Psychiatric disorders and behavioral disturbances are reported to be three to five times more common among people with injuries which are severe enough to require hospital admission. Survivors commonly develop psychiatric problems like depressive disorder(10).

The combination of orthopaedic trauma and depressive disorder is a particularly potent cause of disability and it affects the outcome of a disease(11). In Sodo town most of the musculoskeletal injuries result from road traffic accidents which constitute the bulk of orthopaedic trauma patients seen in an emergency, inpatient and the out-patients department of Sodo Christian general hospital and Sodo university teaching Referral hospital $(12,13)$.

The problem of orthopaedic trauma is increasing rapidly due to the expansion of the road network and the increase in the number of vehicles without adequate quality control has led to a rapid rise in the number of road traffic accidents, and it is the leading cause of disability and death(14). Despite the burden of trauma little is known about the psychiatric squeal specifically depression in orthopeadic trauma patients. Early detection and proper management of psychiatric squeal in orthopaedic trauma play a vital role in the physical functional and occupational outcomes of patients. Therefore, the aim of this study is to address this gap by assessing the prevalence of depression and associated factors among orthopaedic trauma patients attending outpatient clinics in Sodo town hospitals.

\section{Methods And Materials}

\section{Study setting, design and period}

All method sections were done according to standard guidelines and procedures of observational methods. Institution based cross sectional study was conducted in Sodo town, Wolaita zone, Southern Ethiopia. The study was conducted at Wolaita Sodo University Teaching Referral Hospital and Sodo Christian General Hospital (SCH). Wolaita Sodo University Teaching Referral Hospital is situated at Sodo town. It is $380 \mathrm{~km}$ from Addis Ababa capital city of Ethiopia, and $165 \mathrm{~km}$ west of regional town, 
Hawassa. It is serving in a catchment area of about 3 Million people including neighboring Dawuro Zone, Gamo Zone, Gofa Zone, and Kembata Tambaro Zone. Orthopaedic clinic is one of the main departments at the outpatient, inpatient, and physiotherapy. The hospital is serving over 6084 orthopaedic Outpatient visitors in a year and around 52 orthopeadic beds with 200 average number of admission per month (13).

Sodo Christian General Hospital ( $\mathrm{SCH}$ ) is a private hospital located in Sodo town. It was established on January 9, 2005. The Hospital is serving for around 3 million people. The hospital is well known for its orthopedic services, having Ethiopian and foreign health professionals. It had 200 beds and is one of 9 training sites in Africa for the pan African academy of Christian Surgeons $(12,15)$.

Source and study population

All orthopaedic trauma patients who are visiting for follow up and new care at Wolaita Sodo University teaching referral hospital and Sodo Christian general hospital. All orthopaedic trauma patients who needs follow up, new care and age 18 years above at Wolaita Sodo University teaching referral hospital and Sodo Christian general hospital.

\section{Inclusion and exclusion criteria}

All adult orthopaedic trauma patients age 18 years and above who attend the orthopaedic clinic during the study period were included the study. All orthopaedic trauma patients who were unable to communicate an admitted to ward were excluded.

\section{Dependant variable: Depression was the dependent variable.}

\section{Independent variables}

Socio demographic variables; Age, Sex, Marital status, Educational level, Occupation. Psychosocial and behavioural characteristics; Social support, substance use and chronic medical disease. Injury characteristics; severity of injury, Site of injury. Multiple site injury. Causes of trauma; road traffic accident, falls, fighting injury. Treatment out comes; - complication, amputation.

\section{Operational definition}

Depression: was measured by using 9 item questions based on Patient Health Questioner nine [PHQ9] (16). Each having a 4-point Likert scale questions (rated as Not at all $=0$, Several days $=1$, More than half the day $=2$, and Nearly every day $=3$ ). The respondents who scored $\geq 5$ were considered as depressed and those who scored $<5$ were not depressed (16). 
Social support it included 6- items that was assess the number of available social support. High social support- Based on the SSQ- 6 respondents who scored $>3$ were considered as having high social support. Low social support- Based on the SSQ- 6 respondents who scored $<3$ were considered as having low social support (17).

\section{Sample size determination}

Sample size was determined by using double population proportion formula. The following assumptions: with confidence interval $(\mathrm{Cl})$ of $95 \%(\mathrm{Za} / 2,1.96)$, power $80 \%$, and ration was used. The complication as a factor was used as percent of unexposed with depression $32.7 \%$ and adjusted odds ratio is 1.94 with $10 \%$ non-response was used (18). The calculated sample size was 359.

\section{Sampling procedure}

A systematic random sampling technique was applied to select study units at orthopaedic outpatient clinics during the study period. The average patients attending orthopaedic outpatient clinic at one month period at WSUTRH and at Sodo Cristian general hospital were $114 \& 1331$, respectively. The study participants were selected from those two hospitals by proportionally allocated sampling method. Therefore the sampling interval $(k)$ was $1445 / 359=4$ Then every $4^{\text {th }}$ patients at the OPD clinic who met the inclusion criteria was interviewed.

\section{Data collection instrument}

A structured patient health questionnaires-9 were used to measure the depression status. It has 9 items and for every item, there is a value from 0 to 3 (not at all $=0$; several days $=1$; more than half of the days $=2$; nearly every day $=3$ ) and by adding the value; the depression status was determined as depressed or not. The PHQ-9 has acceptable reliability, validity and a sensitivity of $88 \%$ and a specificity of $88 \%$ for depression diagnosis (16).

Social support was assessed by (SSQ-6) it included 6- items that was assess the number of available social support. The number of persons available to provide the type of support. The total score is obtained by summing all 6 items with a possible range of 1 to 6 . From the 6 questions who answered 3 and above indicates having high social support whereas who answered below 3 indicates having low social support(17).

The questionnaire was developed in English and translated into local language wolaitigna and Amharic language and translated back to English language by language expertise who were familiar on the field of area in order to ensure its consistency. The Amharic version and wolaitigna version was used for collecting information after introduction to data collectors and supervisors. It was tested in the field after training.

\section{Data collection procedure}


Data were collected by using interviewer administered questionnaires. Three psychiatric nurses to collect the data and two Masters Supervisors to control and manage the data collection procedure was recruited. They were trained for one day on how to fill the questionnaires, about the ethical principles, confidentiality and data management prior to their involvement for data collection.

\section{Data quality control}

Translation of questionnaire was made from English language to local language wolaitigna and Amharic and translated back to English language by language expertise who were familiar on the field of area in order to ensure its consistency. Pre-test was done by using $5 \%$ of the questionnaires at Dubo general hospital which is out of the study area. The completeness, consistency, and accuracy of the collected data was examined by principal investigator on daily basis manually.

\section{Data processing and analysis}

Data were edited, coded and entered into Epi data version 3.1 and exported to SPSS 20 statistical software for analysis. Descriptive statistics such as mean, median, SD, percent, frequency was done. The data was presented by using tables and graphs. The necessary assumption of logistic regression was checked. Hosmer and Lemeshow goodness-of-fit-test statistics were used to assess the fitness of the model ( $p$-value $\geq 0.05$ ). Multicollinearity was checked by using cut-off point based on variance inflation factor $(\mathrm{VIF})<10$ or tolerance test $>0.1$. Bivariate analysis were done and all explanatory variables which have association with the outcome variable at $p$ value $<0.25$ were selected for multivariable analysis. Then multivariable analysis at $\mathrm{P}$ value $<0.05$ and adjusted Odds Ratio (AOR) with $95 \% \mathrm{Cl}$ was used to measure the degree of association between independent variables and outcome variable.

\section{Result}

\section{Socio-demographic Characteristics}

Total 352 orthopeadic patients were responded which makes $98 \%$ response rate. More than half, $193(54.8 \%)$ of respondents were male. Mean age were 34.5 years of and maximum age interval is 18 to 29 years that accounts $129(36.6 \%)$. Educational level of respondents showed that, 45(12.9\%) and139 $(39.5 \%)$ were unable to read and write, 9-12 grade respectively. Marital status of the respondents, $225(63.9 \%)$, were married. The majority of respondents $234(66.5 \%)$ were living at urban residence. Regarding to income of the respondents, majority of the respondents monthly income $273(77.6 \%)$ were $>1000$ birr (table 1).

Table 1. Socio demographic characteristics of outpatient orthopaedic attendants, Southern Ethiopia, $2020(\mathrm{~N}=352)$ 


\begin{tabular}{|c|c|c|c|}
\hline Variable & & Frequency & Percent \\
\hline \multirow[t]{2}{*}{ Sex } & Male & 193 & 54.8 \\
\hline & Female & 159 & 45.2 \\
\hline \multirow[t]{4}{*}{ Age } & $18-29$ & 129 & 36.6 \\
\hline & $30-39$ & 99 & 28.1 \\
\hline & $40-49$ & 82 & 23.3 \\
\hline & $>=50$ & 42 & 11.9 \\
\hline \multirow[t]{4}{*}{ Marital status } & Married & 225 & 63.9 \\
\hline & Single & 103 & 29.3 \\
\hline & Divorced & 18 & 5.1 \\
\hline & Widowed & 6 & 1.7 \\
\hline \multirow[t]{4}{*}{ Educational status } & Unable to read write & 100 & 28.4 \\
\hline & $1-8$ & 53 & 15.1 \\
\hline & $9-12$ & 139 & 39.5 \\
\hline & College and above & 60 & 17.0 \\
\hline \multirow[t]{2}{*}{ Residence } & Urban & 234 & 66.5 \\
\hline & Rural & 118 & 33.5 \\
\hline \multirow[t]{2}{*}{ Monthly Income } & $<=1000$ & 79 & 22.4 \\
\hline & $>1000$ & 273 & 77.6 \\
\hline
\end{tabular}

\section{Clinical and psychosocial characteristics}

Two third, 251(71.1\%) of respondents had high social support. Majority 295(83.8\%) of respondents were not use substance but $3(0.9 \%)$ of respondents were use drug. Medical condition of respondents showed that, $110(31.3 \%)$ had chronic medical illness. Fifty four percent (192) of them had injured lower limb. The majority of respondents $213(60.5 \%)$ were injured by road traffic accident. Three hundred thirty three (94.6\%), 115(32.7\%) and $63(17.9 \%)$ of the respondents had pain, complication and amputation respectively (table 2 ).

Table 2. Clinical and psychosocial characteristics of outpatient orthopaedic attendants, Southern Ethiopia, $2020(\mathrm{~N}=352)$ 


\begin{tabular}{|c|c|c|c|}
\hline Variable & & Frequency & Percent \\
\hline \multirow[t]{2}{*}{ Social support } & low social support & 101 & 28.7 \\
\hline & high social support & 251 & 71.3 \\
\hline \multirow[t]{2}{*}{ Substance use } & Yes & 57 & 12.2 \\
\hline & No & 295 & 83.8 \\
\hline \multirow[t]{4}{*}{ Type of Substance } & Alcohol & 31 & 8.8 \\
\hline & Drug & 3 & 0.9 \\
\hline & Kchat cheweing & 20 & 5.6 \\
\hline & Cigarette smoking & 3 & 0.9 \\
\hline \multirow[t]{2}{*}{ Chronic medical disease } & Yes & 110 & 31.3 \\
\hline & No & 242 & 68.8 \\
\hline \multirow[t]{5}{*}{ Site of injury } & Upper limb & 59 & 16.8 \\
\hline & Lower limb & 192 & 54.5 \\
\hline & Upper and lower limb & 85 & 24.1 \\
\hline & Hip & 12 & 3.4 \\
\hline & Abdomen & 4 & 1.1 \\
\hline \multirow[t]{3}{*}{ Cause of injury } & Road traffic accident & 213 & 60.5 \\
\hline & Falling down & 136 & 38.6 \\
\hline & Gunshot & 3 & 0.9 \\
\hline \multirow[t]{2}{*}{ Pain } & No & 19 & 5.4 \\
\hline & Yes & 333 & 94.6 \\
\hline \multirow[t]{2}{*}{ Complication } & No & 237 & 67.3 \\
\hline & Yes & 115 & 32.7 \\
\hline \multirow[t]{2}{*}{ Amputation } & No & 289 & 82.1 \\
\hline & Yes & 63 & 17.9 \\
\hline
\end{tabular}

\section{Magnitude of depression}

This study showed that $128(36.4 \%)$ of respondents were depressed at $95 \% \quad \mathrm{Cl}=(31.4,41.4)$ (table 3$)$.

Table 3. Description of depression of outpatient orthopaedic attendants, Southern Ethiopia, 2020 ( $N=352)$ 


\begin{tabular}{|c|c|c|c|c|c|}
\hline s.no & Questions & $\begin{array}{l}\text { Not at } \\
\text { all(0) }\end{array}$ & $\begin{array}{l}\text { Several } \\
\text { Days(1) }\end{array}$ & $\begin{array}{l}\text { More than } \\
\text { half the } \\
\text { day(2) }\end{array}$ & $\begin{array}{l}\text { Nearly } \\
\text { every } \\
\text { day(3) }\end{array}$ \\
\hline 1 & $\begin{array}{l}\text { Little interest or pleasure in doing } \\
\text { things }\end{array}$ & $40(11.4 \%)$ & $54(15.3 \%)$ & $245(69.6 \%)$ & $13(3.7 \%)$ \\
\hline 2 & $\begin{array}{l}\text { Feeling down, depressed, or } \\
\text { hopeless }\end{array}$ & $31(8.8 \%)$ & $19(5.4 \%)$ & $249(70.7 \%)$ & $53(15.1 \%)$ \\
\hline 3 & $\begin{array}{l}\text { Trouble falling or staying asleep, or } \\
\text { sleeping too }\end{array}$ & $14(4 \%)$ & $17(4.8 \%)$ & $273(77.6 \%)$ & $48(13.6)$ \\
\hline 4 & Feeling tired or having little energy & $41(11.6 \%)$ & $10(2.8 \%)$ & $265(75.3)$ & $36(10.2 \%)$ \\
\hline 5 & Poor appetite or overeating & $32(9.1 \%)$ & $18(5.1 \%)$ & $266(75.6 \%)$ & $36(10.2 \%)$ \\
\hline 6 & $\begin{array}{l}\text { Feeling bad about yourself- or that } \\
\text { you are a failure or have let yourself } \\
\text { or your family down }\end{array}$ & $59(16.8 \%)$ & $31(8.8 \%)$ & $176(50 \%)$ & $86(24.4 \%)$ \\
\hline 7 & $\begin{array}{l}\text { Trouble concentrating on things, } \\
\text { such as reading the newspaper or } \\
\text { watching Television }\end{array}$ & $53(15.1 \%)$ & $34(9.7 \%)$ & $178(50.6 \%)$ & $87(24.7 \%)$ \\
\hline 8 & $\begin{array}{l}\text { Moving or speaking so slowly that } \\
\text { other people could have noticed? Or } \\
\text { the opposite being so fidgety or } \\
\text { restless that you have been moving } \\
\text { around a lot }\end{array}$ & $68(19.3 \%)$ & $35(9.9 \%)$ & $152(43.2 \%)$ & $97(27.6 \%)$ \\
\hline 9 & $\begin{array}{l}\text { Thoughts that you would be better } \\
\text { off dead or of hurting yourself in } \\
\text { some way }\end{array}$ & $62(17.6 \%)$ & $15(4.3 \%)$ & $224(63.6 \%)$ & $51(14.5 \%)$ \\
\hline 10 & Level of depression & \multicolumn{2}{|l|}{ Depressed } & \multicolumn{2}{|c|}{$128(36.4 \%)$} \\
\hline & & \multicolumn{2}{|c|}{ Not depressed } & \multicolumn{2}{|c|}{$224(63.4 \%)$} \\
\hline
\end{tabular}

\section{Factors associated with depression}

In the multivariable logistic regression analysis pain, amputation, complication, multiple site injury were found to have statistically significant association (at $p$-value $<0.05$ ). Those who developed complication were 5.6 times more likely to had depression compared with respondents who didn't develop complication, [AOR, 5.6, 95\% Cl (3.02-10.38)]. Patients who have pain were 1.99 times more to have depression compared with respondents who haven't pain, [AOR 4.42, 95\% $\mathrm{Cl}$ (1.49-13.1)]. Patients who had multiple site injury were 2.6 times more have depression as compared with respondents who have not multiple site injury [AOR=2.6, 95\% $\mathrm{Cl}(1.005-6.64)]$. Patients who amputated were,3.2 times more to have depression as compared with respondents who did not amputated [AOR 3.2, 95\% Cl (1.64-6.1)] (table 4). 
Table 4. Associated factors of depression outpatient orthopaedic attendants, Southern Ethiopia, 2020 $(\mathrm{N}=352)$ 


\begin{tabular}{|c|c|c|c|c|c|}
\hline \multirow[t]{2}{*}{ Variable } & & \multicolumn{2}{|c|}{ Depression Status } & \multicolumn{2}{|c|}{$\begin{array}{l}\text { OR( } 95 \% \text { confidence } \\
\text { interval) }\end{array}$} \\
\hline & & $\begin{array}{l}\text { Depressed } \\
(n=128)\end{array}$ & $\begin{array}{l}\text { Not } \\
\text { depressed } \\
(n=224)\end{array}$ & $\begin{array}{l}\operatorname{COR}( \\
95 \% \mathrm{Cl})\end{array}$ & $\begin{array}{l}\text { AOR } \\
(95 \% \mathrm{Cl})\end{array}$ \\
\hline \multirow[t]{4}{*}{ Education } & $\begin{array}{l}\text { Unable to read } \\
\text { write }\end{array}$ & $48(48 \%)$ & $52(52 \%)$ & $\begin{array}{l}2.5(1.27- \\
5.08)\end{array}$ & $\begin{array}{l}1.01(0.4- \\
2.549)\end{array}$ \\
\hline & $1-8$ & $10(18.9 \%)$ & 43(81.1\%) & $\begin{array}{l}0.64(0.26- \\
1.56)\end{array}$ & $\begin{array}{l}0.41(0.145- \\
1.16)\end{array}$ \\
\hline & $9-12$ & $54(38.8 \%)$ & $85(61.2 \%)$ & $\begin{array}{l}1.75(0.9- \\
3.4)\end{array}$ & $\begin{array}{l}0.714(0.298- \\
1.71)\end{array}$ \\
\hline & $\begin{array}{l}\text { Collage and } \\
\text { above }\end{array}$ & $16(26.7 \%)$ & $44(73.3 \%)$ & 1 & 1 \\
\hline \multirow[t]{2}{*}{ Residence } & Urban & 78(33.3\%) & $156(66.7 \%)$ & 1 & 1 \\
\hline & Rural & $50(42.4 \%)$ & $68(57.6 \%)$ & $\begin{array}{l}1.47(0.93- \\
2.32)\end{array}$ & $\begin{array}{l}1.75(0.94- \\
3.27)\end{array}$ \\
\hline \multirow[t]{2}{*}{ social support } & $\begin{array}{l}\text { Low social } \\
\text { support }\end{array}$ & $49(48.5 \%)$ & $52(51.5 \%)$ & $\begin{array}{l}2.052(1.28- \\
3.29)\end{array}$ & $\begin{array}{l}0.999(0.54- \\
1.854)\end{array}$ \\
\hline & $\begin{array}{l}\text { high social } \\
\text { support }\end{array}$ & 79(31.5\%) & $172(68.5 \%)$ & 1 & 1 \\
\hline \multirow{2}{*}{ Complication } & Yes & $66(57.4 \%)$ & $49(42.6 \%)$ & $\begin{array}{l}3.8(2.38- \\
6.08)\end{array}$ & $\begin{array}{l}5.6(3.02- \\
10.38)^{*}\end{array}$ \\
\hline & No & $62(26.2 \%)$ & $175(73.8 \%)$ & 1 & 1 \\
\hline \multirow[t]{2}{*}{ Is there any pain } & Yes & $10(52.6 \%)$ & $9(47.4 \%)$ & $\begin{array}{l}2.024(0.8 \\
5.12)\end{array}$ & $\begin{array}{l}4.42(1.49- \\
13.1)^{\star}\end{array}$ \\
\hline & No & $118(35.4 \%)$ & $215(64.6 \%)$ & 1 & 1 \\
\hline \multirow[t]{2}{*}{ Multiple injury } & Yes & $36(46.8 \%)$ & $41(53.2 \%)$ & $\begin{array}{l}1.75(1.05- \\
2.92)\end{array}$ & $\begin{array}{l}2.6(1.005- \\
6.64)^{\star}\end{array}$ \\
\hline & No & $92(33.5 \%)$ & $183(66.5 \%)$ & 1 & 1 \\
\hline \multirow[t]{2}{*}{$\begin{array}{l}\text { Previous history of } \\
\text { chewing kchat }\end{array}$} & Yes & $37(42.5 \%)$ & $50(57.5 \%)$ & $\begin{array}{l}1.42(0.86- \\
2.32)\end{array}$ & $\begin{array}{l}0.415(0.112 \\
-1.54)\end{array}$ \\
\hline & No & $91(34.3 \%)$ & $174(65.7 \%)$ & 1 & 1 \\
\hline \multirow[t]{2}{*}{$\begin{array}{l}\text { Currently chewing } \\
\text { kchat }\end{array}$} & Yes & $30(49.2 \%)$ & $31(50.8 \%)$ & $\begin{array}{l}1.91(1.091- \\
3.33)\end{array}$ & $\begin{array}{l}2.57(0.813- \\
8.13)\end{array}$ \\
\hline & No & $98(33.7 \%)$ & 193(66.3\%) & 1 & 1 \\
\hline Is there amputation & No & $93(32.2 \%)$ & $196(67.8 \%)$ & 1 & 1 \\
\hline
\end{tabular}




\begin{tabular}{|c|c|c|c|c|c|}
\hline & Yes & $35(55.6 \%)$ & $28(44.4 \%)$ & $\begin{array}{l}2.63(1.51- \\
4.59)\end{array}$ & $\begin{array}{l}3.2(1.64- \\
6.1)^{*}\end{array}$ \\
\hline \multirow[t]{2}{*}{$\begin{array}{l}\text { Chronic medical ill } \\
\text { ness }\end{array}$} & Yes & $45(40.9 \%)$ & $65(59.1 \%)$ & $\begin{array}{l}1.33(0.83- \\
2.11)\end{array}$ & $\begin{array}{l}1.62(0.339- \\
1.123)\end{array}$ \\
\hline & No & $83(34.3 \%)$ & $159(65.7 \%)$ & 1 & 1 \\
\hline \multirow[t]{2}{*}{ Duration of injury } & $<3$ months & $101(43.2 \%)$ & $133(56.8 \%)$ & 1 & 1 \\
\hline & $>=3$ months & $27(22.9 \%)$ & $91(77.1 \%)$ & $\begin{array}{l}0.39(0.24- \\
0.65)\end{array}$ & $\begin{array}{l}0.46(0.25- \\
1.82)\end{array}$ \\
\hline \multirow[t]{4}{*}{ Age } & $18-29$ & $51(39.5 \%)$ & $78(60.5 \%)$ & 1 & 1 \\
\hline & $30-39$ & $28(28.3 \%)$ & $71(71.7 \%)$ & $\begin{array}{l}0.6(0.34- \\
1.1)\end{array}$ & $\begin{array}{l}0.49(0.22- \\
1.1)\end{array}$ \\
\hline & $40-49$ & $28(34.1 \%)$ & $54(65.9 \%)$ & $\begin{array}{l}0.793(0.45- \\
1.41)\end{array}$ & ${ }_{1.81)}^{0.81(0.36-}$ \\
\hline & $>=50$ & $21(50 \%)$ & $21(50 \%)$ & $\begin{array}{l}1.53(0.759- \\
3.08)\end{array}$ & $\begin{array}{l}1.86(0.68- \\
5.06)\end{array}$ \\
\hline
\end{tabular}

* Statistical significant with depression

\section{Discussion}

The prevalence of depression was $36.4 \%$ with $95 \% \mathrm{Cl}=(31.4-41.4)$ among outpatient orthopaedic attendants. Depression was affected by complication of injury, pain, multiple site injury and amputation.

The prevalence of depression in this study was similar to the finding of study conducted in Addis Ababa,TikurAnbesa specialized hospital(36,1\%)(18), Malaysia (38\%) (19), in Indian (36\%) (20) ,Brazil (33\%) (21), and UK (30.3\%) (7). On the other hand this finding is higher than the findings of other studies conducted at China $(23.5 \%)(9)$, Brazil $(23 \%)(21)$, Jordan $(20 \%)(21,22)$, USA(12\%)(7). This finding is lower than the study conducted at Indian orthopeadic patients $87.6 \%$ (3) and at Massachusetts general hospital was (45\%)(23). This differences might be time of study period, socio-demographic, like educational, economic and cultural factors of the current study area and study settings, composite scoring, type of depression measurement tool they used and type of healthcare facilities.

Patients who developed complication were more likely to have depression as compared with who did not develop complication, This finding was similar to the study conducted in Tikur Anbesa specialized hospital (18). This might be due to immunity suppression and neurotransmitter disturbances.

Patients with pain were more depressed compared with those who have not pain. This finding is similar to the study performed in Adiss Ababa tikur Anbessa specialized hospital (18). This may be due to increased discomfort on patients which leads to increased emotional distress. It may also be due to the fact that pain is shown to cause altered synaptic connectivity at the prefrontal cortex and hippocampus. 
Respondents who had multiple site injury were more have depression compared with respondents who had single site injury. This finding was similar to the study conducted at Tikure Anbesa specialized hospital(18).

This study showed that respondents who amputated were more have depression compared with respondents who did not amputated. This is in line with the study conducted at Tikur anbessa specialized hospital(18). As a limitation of study doesn't addressed inpatients and patients below 18 years.

\section{Conclusion And Recommendation}

The prevalence of depression was high in orthopaedic outpatient clinics at southern Ethiopia. Having pain, complication, being amputation and multiple site injury were predictors of depression.

Hospitals should strengthen collaboration between the Orthopaedic clinic and mental health department of hospitals to ensure a holistic management of trauma patients taking care of both their physical and mental health. Further studies are recommended in orthopaedic trauma clinics to document the prevalence and factors associated with depression and the outcomes of depression in orthopaedic trauma patients most especially in developing countries like Ethiopia.

\section{List Of Abbreviations And Acronyms}

\begin{tabular}{|ll|}
\hline AOR & Adjusted odds ratio \\
\hline Cl & confidence interval \\
COR & Crude odds ratio \\
\hline ERC & Ethical review committee \\
\hline SCGH & Sodo Christian general hospital \\
\hline SNNPR & South Nation Nationality Region \\
\hline SPSS & Statistical Package for Social Science \\
\hline UK & United Kingdom \\
\hline USA & United States of America \\
\hline WHO & World Health Organization \\
\hline WSUTRH & Wolaita Soda University Teaching Referral HospitalDeclarations \\
\hline
\end{tabular}

\section{Declarations}

Ethical approval and consent to participate: Ethical approval and clearance was obtained from Ethical Review committee (ERC) of Wolaita Sodo University college of health science and medicine. Permission was also obtained from concerned bodies of Wolaita Sodo University teaching and referral hospital, and 
Sodo Christian General Hospital. Informed written consent was obtained from study participants Orthopeadic patients after clear explanation is given about the aim of the study. Confidentiality and privacy was maintained during data collection, analysis and reporting in which the information obtained from the respondents was not be shared with anyone other than the data collectors and principal investigator. All method sections were done according to standard guidelines and procedures of observational methods.

Consent for Publication: not applicable.

Availability of Data and Material: The datasets generated and/or analysed during the current study are not publicly available due to ethical issues but are available from the corresponding author on reasonable request.

Financial Disclosure: The research has no received any funding.

Competing interest: the authors declared that they have no conflict of interest.

Author's contribution: AM: Initiated the research, wrote the research proposal, conducted the research, did data entry and analysis, and wrote the manuscript. SBW: Involved in the write-up of the methodology of proposal and research work, analysis, and manuscript write-up. CL: Contributed to the write-up of the proposal and write-up of the manuscript. DW: participated in the write-up of the methodology of the proposal, research work, and write-up of the manuscript. All are equally contributed.

Acknowledgement: We would like to acknowledge Wolaita Sodo University, Wolaita Sodo University teaching and referral hospital and Sodo Christian general hospital orthopaedic clinic staffs for their support and cooperation in providing information, and also mainly for the study participants, data collectors and supervisors.

\section{References}

1. WHO. Depression and Other Common Mental Disorders Global Health Estimates. Global Health Estimates Geneva. 2017;2.

2. Folashade T Alloh PR, Igoche Onche, Edwin van Teijlingen, Steven Trenoweth. mental health in mildle and low incom country. going beyod the for fund. health prospect journal of public health. 2018;17.

3. Ravikant Jain RRBS, Vivek Kiyawat. Role of depression and its associating factors in indoororthopaedic patients. Asian Journal of Medical Sciences 2015;6(6).

4. Haile Tilahun NA, Biftu Geda, and Firehiwot Mesfin. Depression and Associated Factors among Adult Inpatients at Public Hospitals of Harari Regional State, Eastern Ethiopia. pyschaitry journal. 2018.

5. Mesfin HTNABGaF. Depression and Associated Factors among Adult Inpatients at Public Hospitals of Harari Regional State, Eastern Ethiopia. Psychiatry Journal. 1 April 2018;Volume 2018, Article ID 6743520, 
6 pages.

6. Solomon Hailemariam FT, Mekonen Asefa, Henok Tadesse and Girma Tenkolu. The prevalence of depression and associated factors in Ethiopia: findings from the National Health Survey. International Journal of Mental Health Systems. 2012;6(23).

7. Oflazoglu M, Menendez ME, Mudgal CS, Ring D, Chen NCEerste auteur. Prevalence and Factors Associated with Major Depression in Orthopedic Hand and Upper Extremity PatientsHand and Upper Extremity Service, Massachusetts General Hospital. 2016.

8. Andualem Mossie DKaAN. Prevalence and Severity of Depression and Its Association with Substance Use in Jimma Town, Southwest Ethiopia. hindwi. 2016.

9. WHO. (C) World Health Organization 2004. INTERNATIONAL ASSOCIATION FOR THE SURGERY OF TRAUMA AND SURGICAL INTENSIVE CARE. 2《I4.

10. Rahul Rishi BSVKJRR, Balkishan Sharma, Vivek Kiyawat. Asian Journal of Medical Sciences. 2015;6.

11. Crichlow RJA, P. L.Morrison, S. M.Haley, S. M.Vrahas, M. S. Depression in orthopaedic trauma patients. Prevalence and severity. Journal of Bone and Joint Surgery 2006;88.

12. annual plan report of sodo crstiyan general hospital. 2019.

13. wolaita sodo university teaching refferal hospital annual report. 2019.

14. Wanli Lin M, Lina Gong, MMa,. Prevalence of posttraumatic stress disorder among road traffic accident survivors A PRISMA-compliant meta-analysis. open accsess. Lin et al. Medicine (2018) 97:3.

15. Gebrehana ABGKJEFTSMNGE. Prevalence and determinants of post-traumatic stress disorder among road traffic accident survivors: a prospective survey at selected hospitals in southern Ethiopia open accsess. 2020.

16. PATIENT HEALTH QUESTIONNAIRE (PHQ-9). 2005.

17. Psychiatry HeaAoG. psycological distressamong pateants of an orthpeadic out patieant clinic. open accsess. 2010;9;9.

18. Mengesha Srahbzu NY, Tolesa Fanta, Dawit Assefa and Enguday Tirfeneh. Prevalence of Depression and Anxiety and Associated Factors among Patient Visiting Orthopedic Outpatient Clinic at Tikur Anbessa Specialized Hospital,Addis Ababa, Ethiopia. Journal of Psychiatry

2017;17( 1000450).

19. Md. Parvez bin Eusof IzzudinMd AAB, Vengadesh Subramaniam, Puspamary Matthews,Cheong Ai Theng. Prevalence and Related Factors of Depression among Healthcare Personnel at Primary Healthcare 
Centers. Malaysian Journal of Medicine and Health Sciences. Nov 2018.

20. Ambrish Sharma GDC. Study of depressive and anxiety symptoms in patients with orthopedic trauma. Indian Journal of Orthopaedics Surgery. 2016.

21. Hui WU FZ, Wenhong CHENG1, , Ying LIN3 Qian WANG. Factors related to acute anxiety and depression in inpatients with accidental orthopedic injuries. 2017;29.

22. / Ibrahim zHySoA. assessment ofanxietyand depression after lower limb amputation. neuro phsycatri. $2008 ; 4$.

23. BY RENN J. CRICHLOW M, PATRICIA L. ANDRES, SUZANNE M. MORRISON, MPH, STEPHEN M. HALEY, PHD, PT, AND MARK S. VRAHAS, MD. Depression in OrthopaedicTrauma Patients PREVALENCE AND SEVERITY. THE JOURNAL OF BONE AND JOINT SURGERY. 2006;88-A 